\title{
Effect of Pt Concentration on the Grain Growth of TiO2sol-gel Films
}

\author{
Y.J. Jia ${ }^{1 \mathrm{a}}$, Na. $\mathrm{An}^{2 \mathrm{~b}}$, H.N. Chen ${ }^{3 \mathrm{c}}$ and Yi Chen ${ }^{4 \mathrm{~d}}$ \\ ${ }^{1}$ School of Mechanical Engineering, Tianjin Polytechnic University, Tianjin 300387, China \\ ${ }^{2}$ Siemens Mechanical Drive Systems Co., Ltd, Tianjin 300400, China \\ ${ }^{3}$ School of Computer Science and Software Engineering, Tianjin Polytechnic University, Tianjin 300387, China \\ ${ }^{4}$ Department of mechanical engineering, Inha University, 253 Yonghyun Dong, Nam Gu, Incheon, 402- \\ 751 , South Korea \\ ajiayanjun@tjpu.edu.cn, ${ }^{b}$ na.an@siemens.com, ${ }^{c}$ chenhanning@tjpu.edu.cn, ${ }^{d}$ chenyi6970@hotmail.com
}

\begin{abstract}
Pt metallic has been supported on $\mathrm{TiO} 2$ surface using different methods, Here, Pt doped TiO2 (Pt-TiO2) sol gel thin film were successfully produced by reducing chloroplatinc acid ( $\mathrm{H} 2 \mathrm{PtCl6})$. The structures of prepared composites were investigated using X-ray diffraction (XRD). The physical morphologies of the composites were examined using transmission electron microscope (TEM). The grain size of Pt-TiO2 thin film after annealing was also measured by atomic force microscope (AFM) images.
\end{abstract}

Keywords. TiO2, Pt Annealing, Gran size

\section{Introduction}

Recently, extensive research for titanium dioxide (TiO2) has been carried out in efforts to develop variety of application fields including capacitors for photovoltaic cells [1], sensors [2], antireflection films [3], white pigments [4], optical coatings [5], and high density dynamic random access memory devices [6]. TiO2 have three different crystal phases, such as anatase, rutile, and brookite [7]. Rutile is the most common natural form of TiO2. Brookite phase is crystallized in the orthorhombic system and exhibits no photocatalytic activity. Anatase $\mathrm{TiO} 2$ has excellent photocatalytic activity, physical and chemical stabilities and antimicrobial activity [8-11].

Earlier studies have revealed that the photocatalytic activity of $\mathrm{TiO} 2$ can be improved significantly by doping with noble metals such as $\mathrm{Pt}, \mathrm{Au}, \mathrm{Ag}$, etc [12,13]. It is well known that platinization of $\mathrm{TiO} 2$ often shows a high photocatalytic activity. The doping of platinum on $\mathrm{TiO} 2$ can form the Schottky diode barrier among the metalsand the electronic potential barrier at the metal-semiconductor heterojunction, and the platinized $\mathrm{TiO} 2$ traps the photogenerated electrons efficiently [14]. The doping of $\mathrm{Pt}$ on $\mathrm{TiO} 2$ surface has been widely reported to improve photocatalytic performance for the split of water and the degradation of different harmful compounds [15].

In this paper, we report characteristic properties of $\mathrm{TiO} 2$ and $\mathrm{Pt}$ composite including UV-visible spectra, transmission electron microscope (TEM) images, $x$-ray diffraction (XRD) patterns and atomic force microscope (AFM) images.

\section{Experimental details}

Titanium isopropoxide was used as a sol-gel precursor. The metal alkoxide was mixed with ethanol. The resulting solution became a milk color, and white precipitation was observed. Hydrochloric acid was slowly added to the solution with vigorous stirring until the solution become transparent. Various amounts of chloroplatinc acid (H2PtCl6) (8wt. \% in water) was added to the $\mathrm{TiO} 2$ sol-gel solution. Sodium borohydride (NaBH4) was dispersed in ethanol and slowly added into the $\mathrm{H} 2 \mathrm{PtCl} 6 / \mathrm{TiO} 2$ solution to reduce [PtCl6]2- to Pt0. The aged sol was spin coated onto the glass and silicon substrateby spin-coated at $2000 \mathrm{rpm}$ and heated at $200{ }^{\circ} \mathrm{C}$ for $5 \mathrm{~min}$.. UV-visible spectra were obtained with diode array spectrophotometer (Hewlett-Packard $8452 \mathrm{~A}$ ). The sol-gel was diluted to ethanol and drop to the copper TEM grid. Using this copper grid sample, TEM images were obtained with CM200 (Phylips) microscope. The TiO2 thin films coated onto silicon wafer were annealed in agas environment tube furnace (EM Tech).The annealing process started from room temperature to $750^{\circ} \mathrm{C}$ in steps of $5^{\circ} \mathrm{C} / \mathrm{min}$ and then maintained the temperature for $1 \mathrm{~h}$. The films naturally cooled down to room temperature. The $\mathrm{TiO} 2$ thin films doped with Pt were subject to XRD analysis with X'Pert MPD Pro diffractometer (Phylips). The surface of the film also analyzed with NanoScope 3D (Veeco) microscope. 


\section{Results and discussion}

UV-visible spectra of bare $\mathrm{TiO} 2$ and $\mathrm{Pt}-\mathrm{TiO} 2$ prepared with different pt concentration are shown in Figure 1 . The single broad intense absorption peak of Pt-TiO2 between $300-350 \mathrm{~nm}$ can be attributed to the charge-transfer from the valence band to the conduction band. The UV-vis absorption peaks also showed a red shift due to the modification of $\mathrm{TiO} 2$ with $\mathrm{Pt}[16]$.

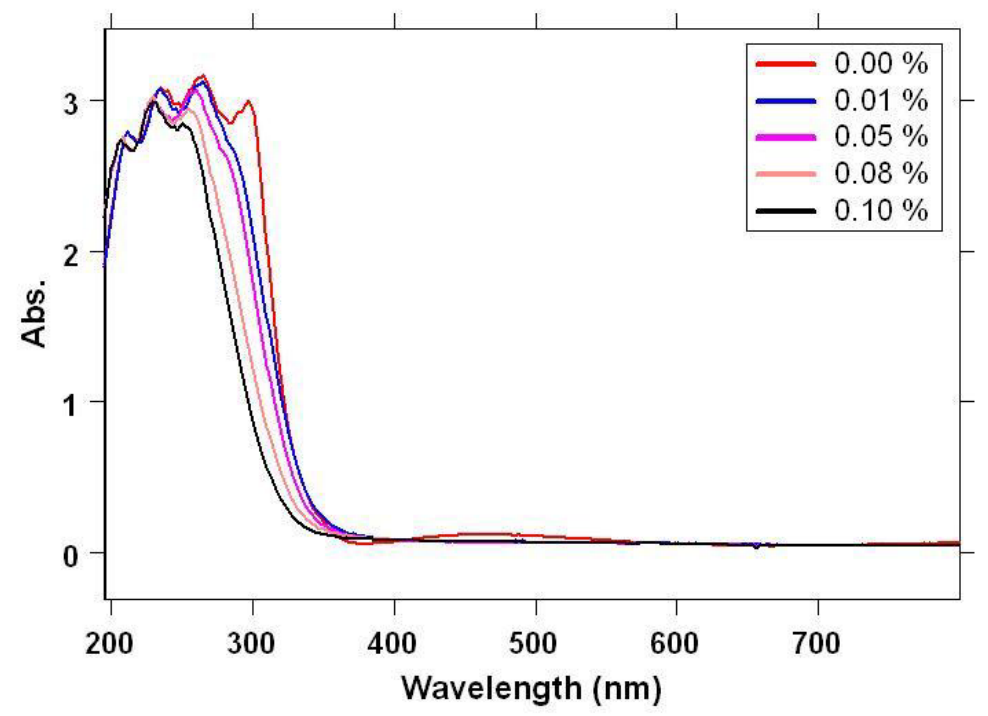

Fig. 1. UV-Visible spectra of bare $\mathrm{TiO} 2$ and Pt-TiO2 sol-gel thin film after annealing.

The UV-visible spectra show the possible uniform distribution of the Pt-nanoparticles throughout the sol-gel films. To obtain the particle size and distribution, the TEM was employed. Figure 2 (a) shows the TEM image for the $0.1 \%$ of Pt-TiO2film with scale bar size of 100 . The aggregated area was further focused and obtained the image with scale bar size of $20 \mathrm{~nm}$ as shown in Figure 2 (b). Pt-nanoparticles do not have big aggregates, distribute relatively uniformly, and distribute particle sizes between $4-8 \mathrm{~nm}$.
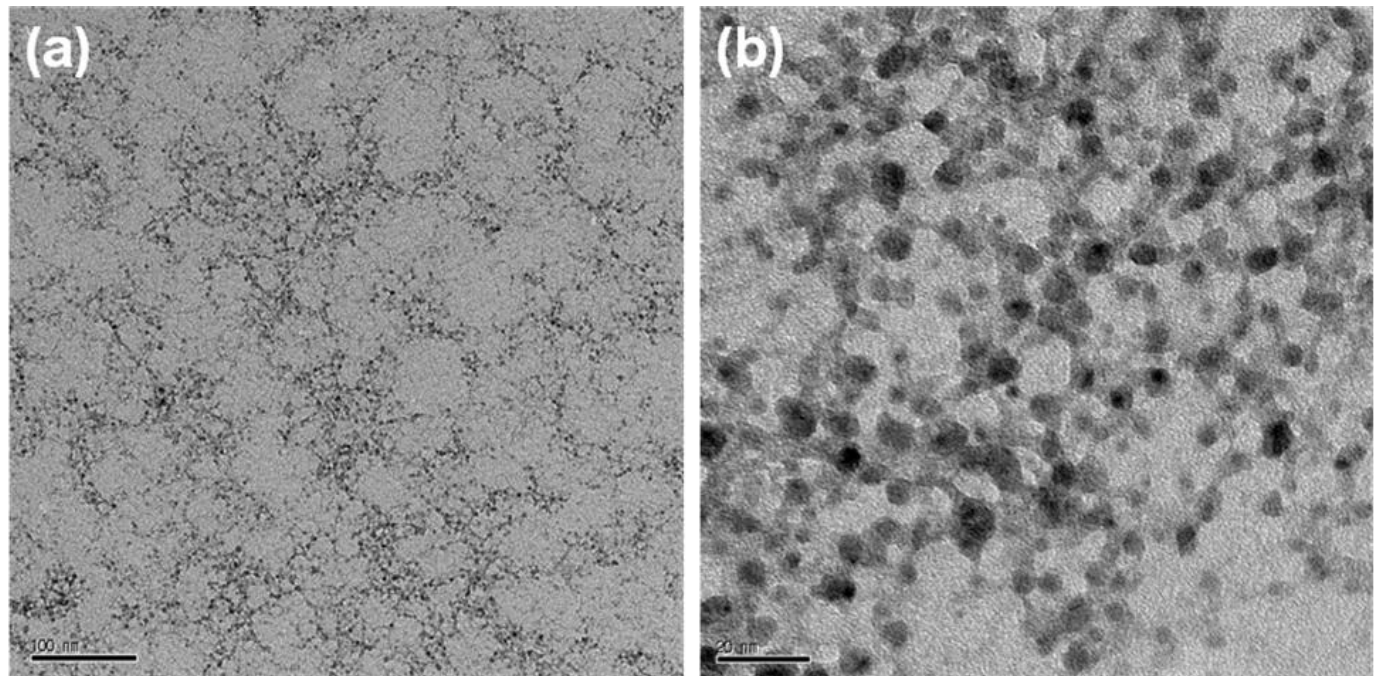

Fig.2. TEM image of $\mathrm{TiO}_{2}-\mathrm{Pt}$ with $0.1 \% \mathrm{Pt}$. 
Figure 3 (a) shows XRD patterns for Pt-TiO2films prepared by sol-gel method with various amount of Pt. All these samples show typical TiO2diffraction peaks in form of anatase. It shows almost coincide with a pure $\mathrm{TiO} 2$ diffraction peaks and shows no diffraction peaks due to the doped Pt. It can be assumed that the amount of Pt doped particle was very low, which resulted in non-appearance of the Pt crystalline peaks $[17,18]$. However, diffraction intensity increased with the increase of $\mathrm{Pt}$ concentration. The crystalline size of the Pt-TiO2 samples after annealing were estimated from line broadening using Scherrer equation based on (101) peak of anatase TiO2 [19].
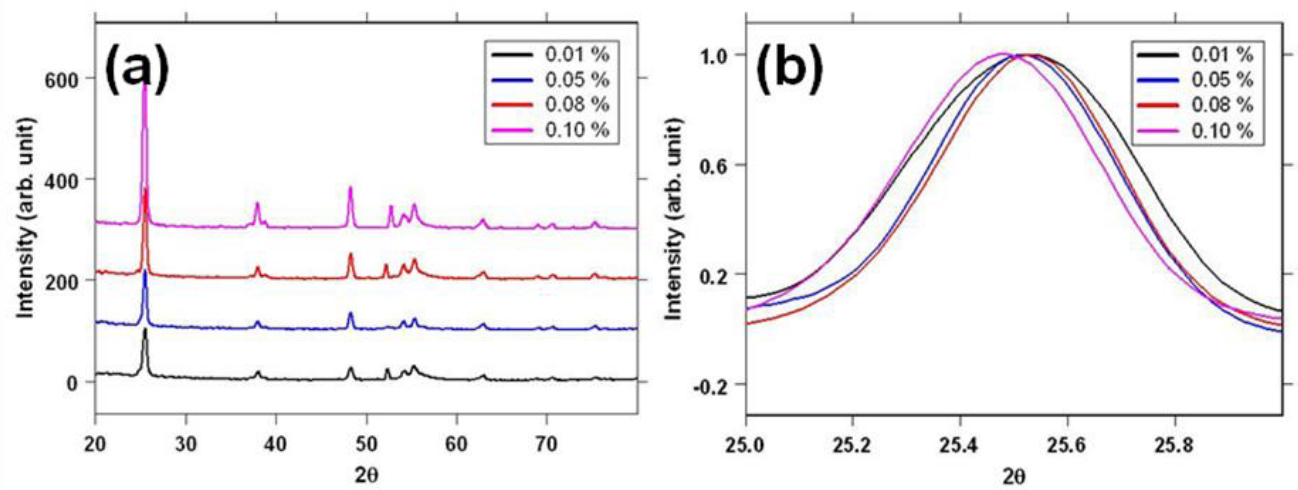

Fig. 3. XRD pattern of $\mathrm{TiO}_{2}$-Pt thin film depends on Pt concentration.

$$
D=0.9 \lambda / \beta \cos \theta
$$

where $\lambda$ is the X-ray wavelength of Copper K $\alpha$ radiation, $\theta$ is Bragg's angle and $\beta$ is the pure full width of the diffraction line at half of the maximum intensity (Figure 3(b)). The calculated grain sizes are $15 \mathrm{~nm}(0.01 \%), 20 \mathrm{~nm}$ $(0.05 \%), 35 \mathrm{~nm}(0.08 \%)$ and $40 \mathrm{~nm}(0.1 \%)$, separately. The result refers to that doping Pt also retard the grain growth of $\mathrm{TiO} 2$ thin film.

AFM images of the Pt-TiO2 surface were used to monitor the grain size of the sol-gel thin film depends on Pt concentration. $1 \mu \mathrm{m} \times 1 \mu \mathrm{m}$ scans revealed it is clear that the grain size of Pt-TiO2 gradually increased with Pt loading.

\section{Conclusions}

Metallic doping is one factor for TiO2anatase phase grain growth. The intensity of the main anatase diffraction peak increased with increasing Pt concentration. The grain sizes estimated from anatase XRD major diffraction peaks were $15,20,35$ and $40 \mathrm{~nm}$ for the sample with Pt concentration of $0.01 \%, 0.05 \%, 0.085$ and $0.1 \%$, respectively. The measured grain sizes using AFM images also increased depends on Pt concentration. The governing factor to determine the grain size of the $\mathrm{TiO} 2$ thin films is Pt doping.

\section{References}

1. H. W. Wang, C.F. Ting, M.K. Hung, C.H. Chiou, Y.L. Liu, Z. Liu, K.R. Ratinac, S.P. Ringer, Nanotechnology, 20 (2009), pp. 055601.

2. J. Bai, B. Zhou, Chem. Rev. 114 (2014), pp. 10131.

3. V. Zoulalian, S. Monge, S. Zrcher, M. Textor, J.J. Robin, S. Tosatti, J. Phys. Chem. B, 110 (2006), pp. 25603.

4. N.B. Chaure, A.K. Ray, R. Capan, Semicond. Sci. Technol. 20 (2005), pp. 788.

5. H. Yaghoubi, N. Taghavinia, E.K. Alamdari, Surf. Coating Tech. 25 (2010) pp. 1562.

6. Q. Li, K. Ali, S. Lulia, P. Christos, H. Xu, P. Themistoklis, Scientific Reports, 4 (2014), pp. 4522.

7. W. Zhang, S. Chen, S. Yu, Y. Yin, J. Crystal Growth, 308 (2007), pp. 122.

8. T. Ohno, K. Sarukawa, M. Matsumura, New J. Chem. 26 (2002), pp. 1167.

9. X.H. Yang, Z. Li, C. Sun, H.G. Yang, C. Li, Chem. Mater. 13 (2011), pp. 3486.

10. G. Fu, P.S. Vary, C. Lin, J. Phys. Chem. B, 109 (2005), pp. 8889.

11. H. Zhang, G. Chen, Environ. Sci. Technol. 43 (2009), pp. 2905.

12. D. Morris, Y. Dou, J. Rebane, C.E.J. Mitchell, R.G. Egdell, Phys. Rev. B, 61 (2000), pp. 13445.

13. M. Enachi, M. Guix, T. Braniste, V. Postolache, V. Ciobanu, V. Ursaki, O.G. Schmidt, I. Tiginyanu, Surf. Eng. Appl. Electrochem. 51 (2015), pp. 3. 
14. W.Y. Park, G.H. Kim, J.Y. Seok, K.M. Kim, S.J. Song, M.H. Lee, C.S. Hwang, Nanotechnology, 21 (2010), pp. 195201.

15. D. Eder, M. Motta, A.H. Windle, Nanotechnology, 20 (2009) 055602.

16. H. Tada, F. Suzuki, S. Yoneda, S. Ito and H. Kobayashi, Phys. Chem. Chem. Phys., 3 (2001), pp. 1376.

17. L. Ravichandran, K. Selvam, B. Krishnakumar, M.. Swaminathan, J. Hazardous Mater, 167 (2009), pp. $763-769$.

18. H. Wang, Z. Wu, Y. Liu, Y. Wang, Chemosphere, 74 (2008), pp. 773-778.

19. M. Beghi, P. Chiurlo, L. Costa, M. Palladino, M.F. Pirini, J. Non-cryst. Solids, 145 (1992), pp. 175. 